\title{
Estimating Nursing Staff of Tehran Hospitals by WHO and Levine Models
}

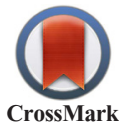

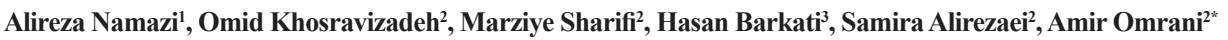

1. Department of Geriatric Nursing, School of Nursing and Midwifery, Tehran University of Medical Sciences, Tehran, Iran.

2. Department of Health Management, School of Health Management and Information Sciences, Iran University of Medical Sciences, Tehran, Iran

3. Department of Public Health, Faculty of Health, Shahid Beheshti University of Medical Sciences, Tehran, Iran.

ditation: Namazi, AR, Khosravizadeh, O, Sharifi, M, Barkati, H, Alirezaei, S \& Omrani, A 2016, 'Estimating Nursing Staff of Tehran Hospitals by WHO and Levine Models', Journal of Client-Centered Nursing Care, vol. 2, no. 2, pp. 73-82. https://doi.org/10.32598/jccnc.2.2.73

: https://doi.org/10.32598/jcenc.2.2.73

Article info:

Received: 14 Dec. 2015

Accepted: 24 Mar. 2016

Keywords:

Estimate nursing staff, WHO model, Levine model

\begin{abstract}
A B S T RA C T
Background: Human resources, especially medical staff is one of the main components of health care system and organizational development. The purpose of this study was to estimate the required nurses for hospitals affiliated to Tehran University of Medical Sciences based on the models of the World Health Organization and Levine.
\end{abstract}

Methods: This study was cross-sectional and descriptive. Seven hospitals affiliated to Tehran University of Medical Sciences were selected as research sample. After collecting data of the number and distribution of the nurses, the data were entered into Excel software. Then, according to the WHO and Levine formula, estimated numbers of hospital nurses were compared with the current situation.

Results: According to the models, the number of nurses in all hospitals was different with standard values. According to WHO model, the correlation was negative and most hospitals but Amir Alam, Baharloo, and Farabi hospitals had insufficient number of nurses. Also, according to Levine model, all hospitals except Bahrami and Amir Alam hospitals had insufficient number of nurses.

Conclusion: According to the World Health Organization and Levine model, the number of nurses in the studied hospitals was inadequate. This imbalance requires proper planning and standards to rectify the shortage of manpower, especially nurses in studied hospitals.

\section{Background}

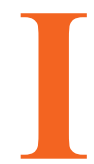

$\mathrm{n}$ the past, the concept of the "work force" was used in the organizations, but today the so-called "human resources" has become common which refers to skilled, well-educated, and experienced staff in the organization. Now, human resources (HR) are considered one of developmental factors in every organization and also one of the main components of health care services. In the health and treatment system, human resources are considered the

\section{* Corresponding Author:}


main capital of an organization, and its shortage can reduce the quality of the care services (Akbari et al. 2011).

In the majority of developing countries, including Iran the health sector consumes about $5 \%$ of the gross domestic product and $5 \%$ to $10 \%$ of government costs. In the future finance and budget issues will be even more significant. Hospitals consume most of the health system budget $(50 \%-89 \%)$. Based on Iran's national statistics, about $40 \%$ of the public health care expenditure is spent on hospitals. Especially in developing countries, hospitals are known with their inefficient management of resources and low profit (Bahadori et al. 2013). HR management in the health sector aims to obtain the desired number and skilled forces in different sectors and their proper distribution both geographically and organizationally. Any flaws in the management and imbalance between supply and demand for human resources in the health sector could lead to the shortage or surplus of human resources. Evidently, the majority of the problems in the hospitals are due to the shortage of staff or their disproportionate distribution. The World Health Organization insists on cutting budgets in the health sector through the human resources (Akbari et al. 2011). In the midst of operating costs of hospitals, the lion's share is the costs of human resources. According to studies and international standards, the cost of human resources is between $55 \%$ and $60 \%$ of the total operating costs (Chatrooz et al. 2011; Farsi et al. 2010).

An important part of the hospital human resources is nursing staff. They play a vital role in enhancing the quality of services and $62 \%$ of employees in the hospitals are nurses (Akbari et al. 2011). The global average number of nurses and midwives is 28 per 10000 people. However, the statistics are different for 6 regions, as it is 68 in Europe, 55 in America, 21 in West Pacific, 14 in Eastern Mediterranean, 11 in Southeast Asia, and 11 in Africa. Many factors are involved in nursing staff services, such as hours of every patient care, care available hours, the volume of work, leaving the job, the absences, and holidays (Chatrooz et al. 2011). Today, health cost is tremendous and hospitals have adopted many solutions to deal with these costs, including limiting hospitalization period as there is a gradual increase of patients to the nurses (Iran-Nejad Parizi 2008). So for proper functioning of hospitals, labor standards should be observed in different hospitals to maintain the required efficiency. In a US study, $75 \%$ of American nurses warned that workload increase in the past two years had a negative impact on care services. In 2005, in Massachusetts, 25\% of the studied nurses associated the death of the patients with staff shortages. The research has confirmed the re- lationship between the number of nurses and the quality of services in hospitals (Iran-Nejad Parizi 2008).

Studies have shown that the shortage of nurses leads to low knowledge and motivation in nurses (Lotfi et al. 2014; Nayeri et al. 2005). In many studies, shortage of nursing staff is one of the major obstacles in achieving productivity and quality services (Pourmohammadi et al. 2014). Therefore, measures should be taken to not only maintain the quality of nurse work in hospitals, but also prevent the recruitment of additional staff, because hiring extra staff causes loss of the budget, reduce productivity, and creates tension and instability. With regard to the importance of the issue, the present study aimed at estimating nurses of hospitals affiliated to Tehran University of Medical Sciences based on the WHO and Levine models. The results can be used for proper planning of HR in hospitals and increasing nursing productivity and overall effectiveness of staff in the hospitals.

\section{Materials \& Methods}

The present study was descriptive and cross-sectional. Research community was all hospitals affiliated to Tehran University of Medical Sciences. In this regard, hospitals of Valiasr, Shariati, Comprehensive Women, Amir Alam, Baharloo, Bahrami, and Farabi were selected as study sample due to the availability of information and co-operation with the hospital authorities. The validity of made researcher form confirmed with teachers and pundits and stability tool not the case because of the purpose of the study. Also, an introduction letter for data collection was received from Iran University of Medical Sciences. After collecting data about the hospitals and their nursing staff, these data were fed to Excel software and in accordance with the WHO and Levine formula, the number of nursing staff needed for every hospital ward was calculated and compared with the real situation in hospitals. To calculate the number of nursing force needed, we used the following formulae:

\section{World Health Organization formula} The number of nurses: the number of bed $\times$ coefficient
occupying the bed $\times$ useful hours care section

\section{Useful working hours In this formula}

- The number of active bed in every part of the hospital is considered;

- Useful work hours in all sectors is 7 hours. 
Useful surveillance hour in any part of hospital are as follows

- Surgery and internal medicine: 5 hours;

- Special care, heart special care, kidney and dialysis: 24 hours;

- Pediatrics and neonates: 6 hours.

Levine model formula

The number of nurses: the number of bed $\times$ days of the year $\times$ (hours of direct care + indirect care)

(Days of the year-unemployed days) $\times$ Useful work hours

\section{In Levine formula components}

- The number of active bed is considered in every part of the hospital;

- The days of the year is 365 day;

- Direct care means watching the bedside of the patient;
- Indirect care means mediated cares like preparing medicine, consultation, planning and reporting for each patient in 24 hours;

- Difference between days of the year and unemployment, give the useful days in the year, which is equivalent to 245 days;

- Useful work hour in all wards is 7 hour;

- Indirect surveillance hour is 0.7 hour.

\section{Hours of direct care}

- Internal medicine, public and surgery: 2.5 hours;

- Balance intensive care unit (Post): 10 hours;

- Special care sectors: 12 hours.

\section{Results}

Out of 7 studied hospitals, 3 were general hospitals and 4 specialist hospitals and all hospitals were educational (Tables 1 \& 2).

Table 1. The number of required nurses in Baharloo Hospital, according to WHO and Levine models.

\begin{tabular}{|c|c|c|c|c|c|c|c|c|c|}
\hline$\frac{20}{\frac{0}{00}}$ & 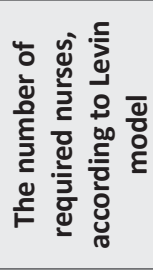 & 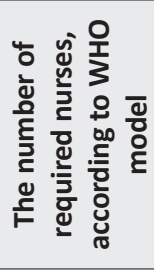 & 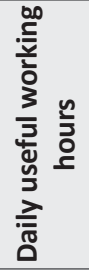 & 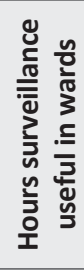 & 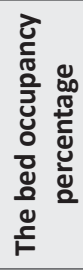 & 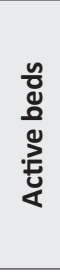 & 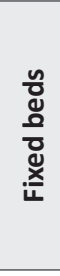 & 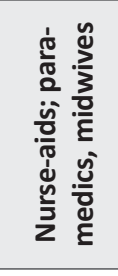 & 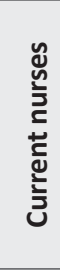 \\
\hline Internal medicine & 22 & 20 & 7 & 5 & 89.66 & 32 & 32 & $0,1,2$ & 15 \\
\hline Surgery & 22 & 17 & 7 & 5 & 70.83 & 32 & 33 & $0,0,3$ & 15 \\
\hline $\begin{array}{c}\text { Gynecology and } \\
\text { pediatrics }\end{array}$ & 22 & 20 & 7 & 6 & 71.25 & 32 & 32 & $1,4,7$ & 9 \\
\hline Poisoning & 14 & 11 & 7 & 5 & 70.83 & 21 & 21 & $0,1,2$ & 12 \\
\hline Neonates & 10 & 7 & 7 & 6 & 60.66 & 14 & 14 & $0,0,5$ & 10 \\
\hline ICU 1 & 22 & 25 & 7 & 24 & 90.41 & 8 & 8 & $0,0,7$ & 19 \\
\hline ICU 2 & 24 & 26 & 7 & 24 & 84.83 & 9 & 9 & $0,0,8$ & 20 \\
\hline ICU 3 & 41 & 45 & 7 & 24 & 88.08 & 15 & 15 & $0,0,12$ & 34 \\
\hline $\mathrm{CCU} 2$ & 15 & 27 & 7 & 24 & 97.33 & 8 & 8 & $0,0,3$ & 11 \\
\hline Post CCU 1 & 19 & 26 & 7 & 24 & 76.33 & 10 & 10 & $0,2,3$ & 11 \\
\hline CCU 1 & 22 & 40 & 7 & 24 & 96.08 & 12 & 12 & $0,1,4$ & 14 \\
\hline Post CCU 2 & 39 & 64 & 7 & 24 & 88.41 & 21 & 21 & $0,1,1$ & 14 \\
\hline Total or average & 272 & 219 & 7 & 16.25 & 82.05 & 165 & 165 & $0,10,58$ & 184 \\
\hline
\end{tabular}

Client-Centered Nursing Care 
Table 2. The number of required nurses in Valiasr Hospital, according to WHO and Levine models.

\begin{tabular}{|c|c|c|c|c|c|c|c|c|c|}
\hline$\frac{\frac{0}{0}}{3}$ & 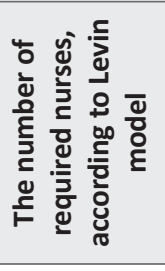 & 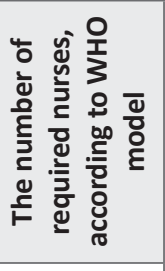 & 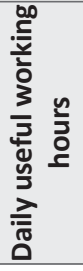 & 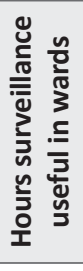 & 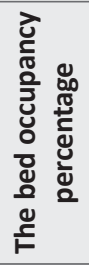 & $\begin{array}{l}\frac{n}{0} \\
\frac{0}{0} \\
\text { 苞 }\end{array}$ & 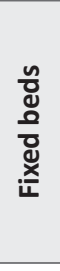 & 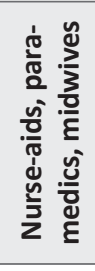 & 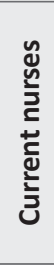 \\
\hline Endocrine glands & 31 & 27 & 7 & 5 & 85 & 45 & 45 & $0,0,1$ & 22 \\
\hline General surgery & 24 & 16 & 7 & 5 & 95.5 & 24 & 24 & $0,0,1$ & 12 \\
\hline ENT & 22 & 22 & 7 & 5 & 97.5 & 32 & 32 & $0,0,1$ & 13 \\
\hline Blood & 16 & 17 & 7 & 5 & 99 & 24 & 24 & $0,0,2$ & 10 \\
\hline BMT & 4 & 3 & 7 & 5 & 81 & 6 & 6 & $0,1,0$ & 3 \\
\hline Surgical \& women oncologist & 31 & 32 & 7 & 5 & 98 & 46 & 46 & $0,0,2$ & 26 \\
\hline NICU 1 & 35 & 42 & 7 & 24 & 96 & 13 & 13 & $0,0,2$ & 27 \\
\hline NICU 2 & 49 & 55 & 7 & 24 & 90 & 18 & 18 & $3,0,3$ & 39 \\
\hline Plastic surgery & 20 & 19 & 7 & 5 & 92 & 30 & 30 & $0,0,2$ & 13 \\
\hline ICU & 22 & 27 & 7 & 24 & 98 & 8 & 8 & $0,0,4$ & 21 \\
\hline Pediatrics & 20 & 16 & 7 & 5 & 75 & 30 & 30 & $0,0,1$ & 11 \\
\hline Thorax & 12 & 11 & 7 & 5 & 87 & 18 & 18 & $0,0,1$ & 8 \\
\hline Total or average & 286 & 287 & 84 & 117 & 91.16 & 294 & 294 & $3,1,20$ & 202 \\
\hline
\end{tabular}

In the following tables, the status quo of nursing staff and its stance with regard to the standards of WHO and Levine models are presented separately for each hospital (Tables 3-7). The average percentage of bed occupancy rate in Baharloo Hospital was $88.41 \%$. Hospital nursing staff was 252 people, including 184 nurses, 58 nurse-aids and 10 paramedics. Desired nursing staff in the hospital, based on an annual average bed occupancy in different wards and according to Levine and WHO models was calculated as 219 and 272 people respectively.

Table 2 shows Valiasr hospital situation, as the chart shows, the average percentage of the bed occupancy rate in hospital was $91.16 \%$, that is the lowest rate for the thorax section (75\%) and the highest rate of $99 \%$ for the blood section. The number of current nursing staff in the hospital was 227 people. The optimum number of nursing staff in the hospital was estimated according to WHO and Levine are 287 and 286 people, respectively.

This hospital had the largest number of sections among study hospitals that its average percentage of bed occupancy was $91.71 \%$. The number of nurses in this hospital was 247 people. The number of required nursing staff in the hospital, according to WHO model was 324 people and based on the Levine model was 306 people. In the hospital, the merger of some sectors caused some additions in the calculation of nursing force needed.

Merger sectors were as follows:

- Medical 1: Rheumatism and Neurology;

- Medical 2: Internal glands, metabolism and internal digestion, liver.

In Table 4 presents the result of comprehensive women hospital. The average percentage of the occupation of the bed in this hospital was $73.55 \%$. The optimum number of nurse staff in the hospital, according to the WHO model was 96 people and based on the Levine model 105 people.

A total of 115 nursing staff at the hospital were busy providing services. The average percentage of hospital beds occupancy in the course of the study was $68 \%$. The number of the desired nursing staff according to WHO and Levine models were 112 and 166 people, respectively. 
Table 3. The number of required nurses in Shariati Hospital, according to WHO and Levine models.

\begin{tabular}{|c|c|c|c|c|c|c|c|c|c|}
\hline$\frac{\frac{0}{20}}{3}$ & 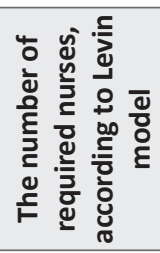 & 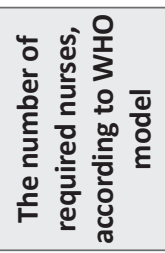 & 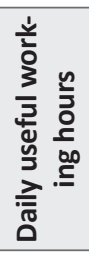 & 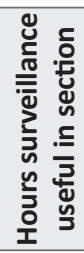 & 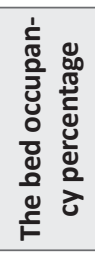 & 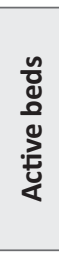 & 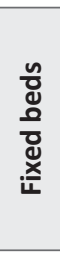 & 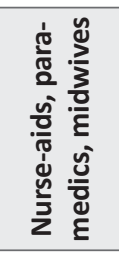 & 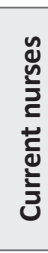 \\
\hline Neonates & 3 & 3 & 7 & 6 & 74.09 & 4 & 4 & $4,2,0$ & 6 \\
\hline $\begin{array}{l}\text { Gynecology and ob- } \\
\text { stetrics }\end{array}$ & 13 & 13 & 7 & 5 & 92.82 & 44 & 44 & $7,2,0$ & 13 \\
\hline Surgery and jaw & 13 & 13 & 7 & 5 & 92.37 & 19 & 19 & $0,1,0$ & 8 \\
\hline Internal medicine & 16 & 11 & 7 & 5 & 93.14 & 16 & 16 & $0,0,0$ & 10 \\
\hline Lung & 20 & 19 & 7 & 5 & 92.61 & 29 & 29 & $0,1,0$ & 14 \\
\hline Heart & 15 & 14 & 7 & 5 & 87.86 & 22 & 22 & $0,0,0$ & 10 \\
\hline Neurosurgery & 16 & 14 & 7 & 5 & 87.12 & 23 & 23 & $0,0,0$ & 11 \\
\hline $\mathrm{CCU}$ & 19 & 33 & 7 & 24 & 96.24 & 10 & 10 & $0,0,0$ & 13 \\
\hline General ICU & 27 & 34 & 7 & 24 & 98.21 & 10 & 10 & $0,0,0$ & 21 \\
\hline Internal ICU & 19 & 24 & 7 & 24 & 99.65 & 7 & 7 & $0,0,0$ & 16 \\
\hline Kidney transplant & 4 & 16 & 7 & 24 & 76.26 & 6 & 6 & $0,1,0$ & 7 \\
\hline $\mathrm{NICU}$ & 16 & 20 & 7 & 24 & 96.49 & 6 & 6 & $0,0,0$ & 10 \\
\hline Surgery 2 (general) & 27 & 25 & 7 & 5 & 86.24 & 40 & 40 & $0,1,0$ & 16 \\
\hline Medical 1 & 23 & 12 & 7 & 5 & 97.59 & 17 & 17 & $0,1,1$ & 15 \\
\hline Medical 2 & 24 & 12 & 7 & 5 & 95.31 & 17 & 17 & $0,0,0$ & 30 \\
\hline Kidney (urology) & 12 & 12 & 7 & 5 & 92.87 & 18 & 18 & $0,1,0$ & 12 \\
\hline ICU \& neurosurgery & 22 & 28 & 7 & 24 & 100.42 & 8 & 8 & $0,0,0$ & 13 \\
\hline Total or average & 306 & 324 & 119 & 200 & 91.71 & 294 & 294 & $11,10,1$ & 225 \\
\hline
\end{tabular}

Table 4. The number of required nurses in Comprehensive Women Hospital, according to WHO and Levine models.

\begin{tabular}{|c|c|c|c|c|c|c|c|c|c|}
\hline$\frac{\text { 잉 }}{3}$ & 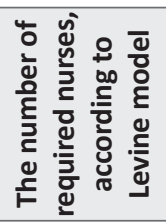 & 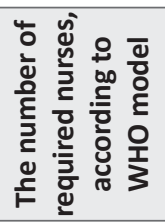 & 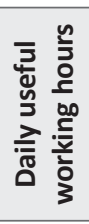 & 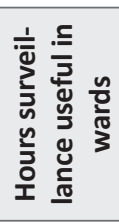 & 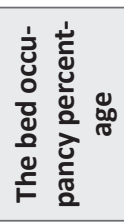 & 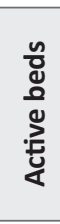 & $\begin{array}{l}\frac{n}{0} \\
\frac{\delta}{0} \\
\frac{d}{4} \\
\frac{x}{4}\end{array}$ & 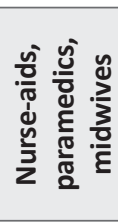 & 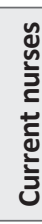 \\
\hline Maternity & 15 & 12 & 7 & 5 & 74.82 & 22 & 22 & $5,0,1$ & 14 \\
\hline Surgery & 25 & 18 & 7 & 5 & 67.31 & 37 & 37 & $6,0,1$ & 14 \\
\hline Oncology & 8 & 8 & 7 & 8 & 57.68 & 11 & 12 & $0,0,0$ & 7 \\
\hline $\mathrm{ICU}$ & 19 & 11 & 7 & 24 & 46.42 & 7 & 7 & $0,0,0$ & 11 \\
\hline $\mathrm{NICU}$ & 32 & 42 & 7 & 24 & 102.87 & 10 & 12 & $0,0,3$ & 31 \\
\hline VIP & 6 & 5 & 7 & 5 & 74.24 & 9 & 9 & $0,0,0$ & 1 \\
\hline Total or average & 105 & 96 & 42 & 71 & 73.55 & 109 & 109 & $11,0,5$ & 78 \\
\hline
\end{tabular}


Table 5. The number of required nurses in Farabi hospital, according to WHO and Levine models.

\begin{tabular}{|c|c|c|c|c|c|c|c|c|c|}
\hline$\frac{\frac{0}{60}}{3}$ & 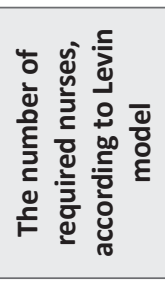 & 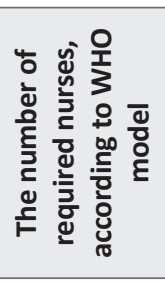 & 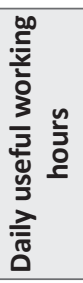 & 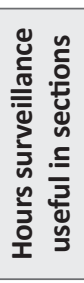 & 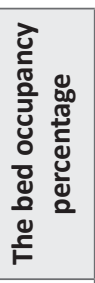 & 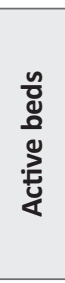 & $\begin{array}{l}\frac{n}{0} \\
\frac{\delta}{0} \\
\frac{\tilde{x}}{4}\end{array}$ & 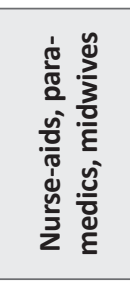 & 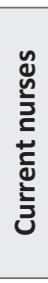 \\
\hline Section A1 & 20 & 15 & 7 & 5 & 70 & 30 & 30 & $2,2,0$ & 12 \\
\hline Section A2 & 24 & 14 & 7 & 5 & 57 & 35 & 35 & $2,1,2$ & 10 \\
\hline Section B1 & 31 & 17 & 7 & 5 & 53 & 46 & 46 & $3,2,2$ & 13 \\
\hline Section B2 & 22 & 14 & 7 & 5 & 63 & 32 & 32 & $2,1,3$ & 11 \\
\hline Section C & 30 & 24 & 7 & 5 & 79 & 44 & 44 & $2,2,1$ & 20 \\
\hline ICU & 24 & 26 & 7 & 24 & 86 & 9 & 9 & $3,3,4$ & 4 \\
\hline Total or average & 166 & 112 & 42 & 49 & 68 & 196 & 619 & $14,11,12$ & 78 \\
\hline
\end{tabular}

The number of nursing staff in the hospital was 144 people. The average occupancy ratio of the hospital beds was $81.37 \%$ during the course of study. The number of nursing staff based on WHO model was estimated to be 138 people and based on the Levine model, it was 131 people.

The average percentage of the bed occupancy, as shown in Table 8 was $64.82 \%$. The number of nurses in hospital was 135 people. According to WHO model 101 people and based on Levine model 131 people was estimated.
In this hospital merger of some sectors has taken place. Merger sectors included internal medicine (men and women), ENT section plus medical (men and women). As seen in Figure 1, in Farabi and Baharloo hospitals, the number of nurses with respect to WHO model is more and based on the model Levine is less. In Valiasr hospital, the number is less than both models. Also in Shariati and Comprehensive Women hospitals, the number of current nursing staff is less than the number of staff estimated by the two models. Based on WHO model, Amir Alam and Baharloo

Table 6. The number of required nurses in Bahrami Hospital, according to WHO and Levine models.

\begin{tabular}{|c|c|c|c|c|c|c|c|c|c|}
\hline$\frac{\frac{0}{6}}{3}$ & 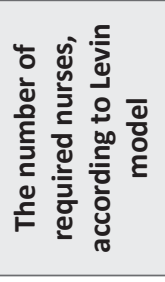 & 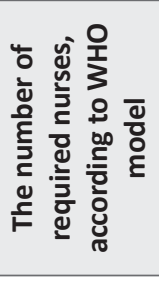 & 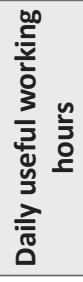 & 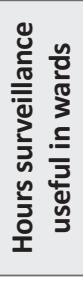 & 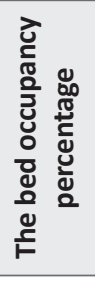 & 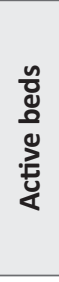 & $\begin{array}{l}\frac{n}{0} \\
\frac{0}{8} \\
\frac{\vec{x}}{4}\end{array}$ & 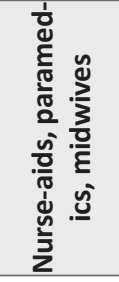 & 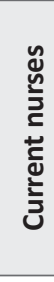 \\
\hline Neonatal care & 14 & 12 & 7 & 6 & 66.20 & 21 & 21 & $0,2,1$ & 13 \\
\hline Pediatric surgery & 14 & 12 & 7 & 5 & 65.19 & 25 & 25 & $1,2,2$ & 11 \\
\hline Infectious ward & 14 & 13 & 7 & 5 & 86.25 & 21 & 21 & $0,2,1$ & 12 \\
\hline $\mathrm{NICU}$ & 32 & 44 & 7 & 24 & 98.13 & 13 & 13 & $3,2,2$ & 25 \\
\hline Internal medicine 1 & 10 & 14 & 7 & 8 & 76.81 & 16 & 16 & $2,1,1$ & 13 \\
\hline Internal medicine 2 & 18 & 11 & 7 & 5 & 82.12 & 18 & 18 & $2,1,1$ & 14 \\
\hline Post ICU & 27 & 32 & 7 & 24 & 93.93 & 10 & 10 & $3,1,1$ & 24 \\
\hline Total or average & 131 & 138 & 49 & 77 & 81.37 & 124 & 124 & $11,11,9$ & 112 \\
\hline
\end{tabular}


Table 7. The number of required nurses in Amir Alam Hospital, according to WHO and Levine models.

\begin{tabular}{|c|c|c|c|c|c|c|c|c|c|}
\hline$\frac{\text { 일 }}{3}$ & 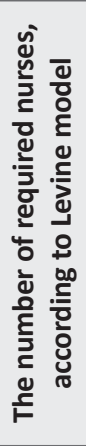 & 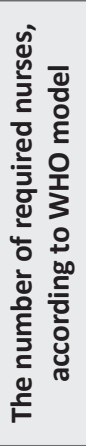 & 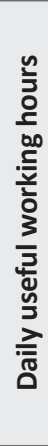 & 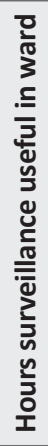 & 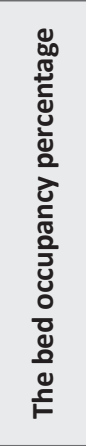 & 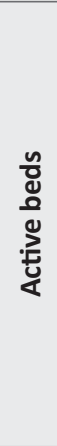 & 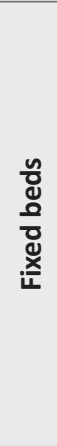 & 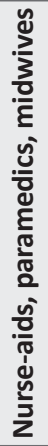 & 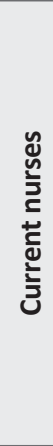 \\
\hline $\begin{array}{l}\text { Internal medicine (men } \\
\text { and women) }\end{array}$ & 19 & 13 & 7 & 5 & 68.08 & 28 & 28 & 7 & 19 \\
\hline $\mathrm{CCU}$ & 26 & 29 & 7 & 24 & 59.53 & 14 & 14 & 3 & 12 \\
\hline ICU & 16 & 15 & 7 & 24 & 73.80 & 6 & 6 & 4 & 15 \\
\hline VIP & 3 & 2 & 7 & 5 & 66.49 & 5 & 5 & 3 & 9 \\
\hline $\begin{array}{c}\text { ENT ward (men and } \\
\text { women) }\end{array}$ & 33 & 22 & 7 & 5 & 64.39 & 48 & 48 & 8 & 28 \\
\hline $\begin{array}{c}\text { Surgery (men and } \\
\text { women) }\end{array}$ & 34 & 20 & 7 & 5 & 56.66 & 50 & 50 & 7 & 20 \\
\hline Total or average & 131 & 101 & 42 & 68 & 64.82 & 151 & 151 & 32 & 103 \\
\hline
\end{tabular}

hospitals have the surplus in nursing staff and Valiasr and Shariati hospitals have a shortage in nursing staff.

As shown in Table 8, in Amir Alam and Baharloo hospitals, the number of nursing staff is more than the estimated number by WHO model. Based on this model, Amir Alam and Baharloo hospital have the most of the surplus in nursing staff and Valiasr and Shariati hospitals are facing with a high shortage in the number of nursing staff. Based on Levine model, all hospitals except Bahrami and Amir Alam have shortage of nursing staff (Table 9).

\section{Discussion}

Hospitals are among the health care system components that their performance will result in coordination with other factors and contributing to society health. In fact, hospitals play a key role in providing health and treatment services (Vatankhah et al. 2014). Therefore, hospitals have a huge impact on the performance of the health system (Rothberg et al. 2005). However, some general hospitals in Iran do not use the full capacity of hospital beds, their bed occupancy ratio is low, use greater number of human resources, and do not use efficiently and

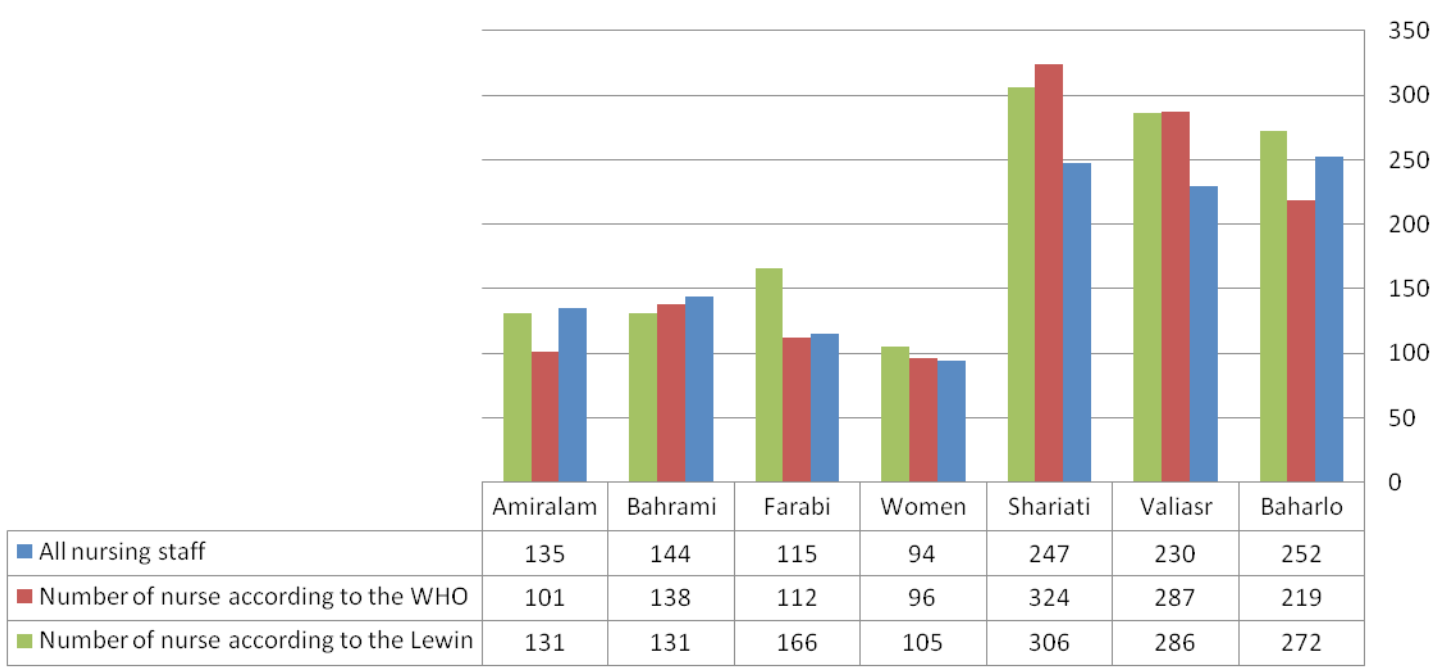

Figure 1. The number of nurses, according to WHO model in all studied hospitals. 
Table 8. The number of current nursing staff and WHO model estimates in the hospitals.

\begin{tabular}{|c|c|c|c|}
\hline Hospital & Difference & WHO model & Current nursing staff \\
\hline Baharloo & +33 & 219 & 252 \\
\hline Valiasr & -57 & 287 & 247 \\
\hline Shariati & -23 & 324 & 94 \\
\hline Women & -2 & 96 & 115 \\
\hline Farabi & +3 & 112 & 144 \\
\hline Bahrami & +6 & 138 & 135 \\
\hline Amir Alam & +34 & 101 & 230 \\
\hline
\end{tabular}

Client-Centered Nursing Care

Table 9. The number of current nursing staff and Levine model estimates in the hospitals.

\begin{tabular}{|c|c|c|c|}
\hline Hospital & Difference & Levine model & Current nursing staff \\
\hline Baharloo & -20 & 272 & 252 \\
\hline Valiasr & -56 & 286 & 247 \\
\hline Shariati & -59 & 306 & 94 \\
\hline Women & -11 & 105 & 115 \\
\hline Farabi & -51 & 166 & 144 \\
\hline Bahrami & +13 & 131 & 135 \\
\hline Amir Alam & +4 & 131 & Client-Centered Nursing Care \\
\hline
\end{tabular}

effectively many of the hospitals and facilities capacities. This will lead to irreparable harm to the nation's health system (Sadeghifar et al. 2011).

In this regard, the results of the present study that showed the micro-level, that nursing staff is unbalanced the office of Health and the organization and management of the country's planning on the number of required nurses, according to the occupation of the coefficient declares If the hospital bed have higher $75 \%$ of the occupation can be 1.5 people per bed with occupying the bed and less, 2.1 people per bed, demand for the position (Sadeghifar et al. 2013). Accordingly, the number of required hospital nursing staff in Baharloo Hospital was less than the standard (Baharloo 247 people, Valiasr 441 people, Shariati 441 people, comprehensive women hospital 130 people, Farabi hospital 235 people, Bahrami Hospital 186 people, Amir Alam 181 people. Sadeghi et al. showed that only $11.29 \%$ of the hospitals met the standards of the Ministry of Health standards, 11.29\% were above the standards, and $77.42 \%$ were below the standards (Sadeghifar et al. 2011).

In the present study and based on the models, most studied hospitals are facing with shortage of staff. With regard to the number of nursing force, $5 \%$ of hospitals were in accordance with the Levine model, 6\% were higher and $89 \%$ of hospital wards were lower than the Levine model. While with regard to WHO model, 10.5\% were in accordance with the model standards, $15 \%$ were higher and $74.5 \%$ were lower. Based on the results of the study, hospitals need to replace workers and nurse-aids with nursing staff, because the total number of healthcare staff, including nurses, paramedics, and nurse-aids were higher than the standard values. Furthermore, their knowledge and expertise in terms of caring service are not beneficial and reduces the efficiency and the balance of power in the healthcare sector. So, by replacing health workers and nurse-aids with nurses, we will have higher effectiveness and efficiency and lower layoffs. Various studies proposed different ways to improve the required 
medical staff. For example, the use of additional personnel in the act as overtime nurses other sectors of nursing will be diminished staff need (Sadeghifar et al. 2013). Entrusting the tasks office clerks sectors in the reduction is effective. Entrusting the tasks patient care from the boys and patient service forces and also admitted it would be very dangerous. So formulation accountabilities of any of the groups and evaluation system based on the establishment of a description of the functions entrusted is necessary.

The study found that according to Levine model, all studied hospitals but Bahrami hospitals and Amir Alam, are facing with the nursing staff shortages that the difference in the hospitals to differences in areas such as the occupation factor, the number of holiday, using the approved bed, or active bed in determining the number of required nurse, considering services trainee students, if entrusting the tasks to non-governmental sector or outside the hospital, the standard of the absence of the number of beds in each sector, being different type of activity and specialized sectors, situation in building indicators, installations, equipment, infrastructure, compared to the area, the workflow and the deployment of relevant units, attributed the knowledge and skills nurses. Regarding these areas, it is necessary that with regard to the differences and the conditions for resolving the deficits each hospital acted.

Finally, to maintain and improve the quality of services provided in hospitals, the basic step is efficient and effective planning. In this regard, it is suggested that nursing job description must be formulated as a spate of targeted and not based on fact and aims to attract new labor and manpower to apply existing and planned with respect to the principles of true manpower jobs until manpower and efficient way to be used by other sources and secondly, a shortage of manpower, especially the nursing staff in the case study is an effective way.

\section{Acknowledgments}

This study was supported by Tehran hospital officials and staff. Thus, the authors appreciate the president, managers, and all staff of the study hospitals who offered their sincere help to conduct this research.

\section{Conflict of Interest}

The authors declared no conflict of interests.

\section{References}

Akbari, F, Kokabi, F \& Yousefian, S 2011, '[Determining nursing manpower needed in a sample hospital (Persian)]', Hospital, vol. 9, no. 3, pp. 69-76.

Bahadori, M, Arab, M, Sadeghifar, J, Ahmadi, B, Salimi, M \& Yaghoubi, M 2013, 'Estimation of nursing staff in selected hospitals of Ilam and Ahvaz Provinces, Western Iran', Nursing $\mathcal{E}$ Midwifery Studies, vol. 2, no. 2, pp. 217-25. PMID: 25414862

Chatrooz, A, Nazari, H, Goudarzi, L, Bakhtiari, M, Nazari, A \& Oghli, BA 2011, 'How to allocate the nursing manpower in the selected hospitals, affiliated with Tehran University of Medical Sciences', International Journal of Advanced Biological and Biomedical Research, vol. 2, no. 6, pp. 1900-906.

Farsi, Z, Dehghan-Nayeri, N, Negarandeh, R \& Broomand, S 2010 'Nursing profession in Iran: an overview of opportunities and challenges', Japan Journal of Nursing Science, vol. 7, no. 1, pp. 9-18. doi: 10.1111/j.1742-7924.2010.00137.x

Iran-Nejad Parizi, M 2008, '[Organization and management from theory to practice Central (Persian)]', Bank Publications, Tehran.

Lotfi, F, Kalhor, R, Bastani, P, Shaarbafchizadeh, N, Eslamian, M, Dehghani, MR et al. 2014, 'Various indicators for the assessment of hospitals' performance status: differences and similarities', Iranian Red Crescent Medical Journal, vol. 16, no. 4, p. e12950. doi: 10.5812/ircmj.12950

Nayeri, N, Nazari, A, Salsali, M \& Ahmadi, F 2005, 'Iranian staff nurses' views of their productivity and human resource factors improving and impeding it: a qualitative study', Human Resources for Health, vol. 3, p. 9. doi: 10.1186/1478-4491-3-9

Pourmohammadi, K, Hatam, N, Bastani, P \& Lotfi, F 2014, 'Estimating production function: a tool for hospital resource management', Shiraz E-Medical Journal, vol. 15, no. 4, p. e23068.doi: $10.17795 /$ semj23068

Rothberg, MB, Abraham, I, Lindenauer, PK \& Rose, DN 2005, 'Improving nurse-to-patient staffing ratios as a cost-effective safety intervention', Medical Care, vol. 43, no. 8, pp. 785-91. PMID: 16034292

Sadeghifar, J, Pourreza, A \& Ahmadi, B 2011, '[Assessment of necessary staff for hospitals of Ilam University of Medical Sciences in accordance with personnel criteria and standards of Iranian Health Ministry (Persian)]', Journal of Ilam University of Medical Sciences, vol. 19, no. 1, pp. 24-31.

Sadeghifar, J, Tofighi, S, Hasani, M, Rekab Eslami, S, Raadabadi, M \& Moosavi, SM 2013, 'Estimation of the necessary nursing manpower in selected hospital affiliated with Jundishapur University of Medical Sciences 2013', Jundishapur Journal of Health Sciences, vol. 5, no. 1, pp. 1-8.

Vatankhah, S, Gorji, H, Khosravizadeh, O \& Mohseni, M 2014, 'The effect of payment method of treatment cost on patient length of stay in educational and healthcare centers in Qazvin, Journal of Health Administration, vol. 17, no. 57, pp. 68-76. 
